\title{
HEMANGIOLYMPHANGIOMA OF THE MANDIBLE: CASE REPORT
}

\author{
Elitsa Deliverska \\ Department of Oral and Maxillofacial surgery, Faculty of Dental medicine, \\ Medical University - Sofia, Bulgaria.
}

\begin{abstract}
Background: Malformations of vascular nature originate as anomalies caused due to errors in vasculogenesis. Vascular anomalies may be found in different combinations of vascular elements, and pathohistologically these elements could be filled with blood and named lymphangiohemangioma or hemangiolymphangioma related to the dominant tissue structure which is presented.

Purpose: The aim of this study is to present a case of vascular malformation diagnosed as hemangiolymphangioma.

Patients and Methods: A case of 46-years' old female patient with histologically proved hemangiolymphangioma of the mandible is implemented. The lesion was asymptomatic and discovered as an incidental finding. The patient underwent surgical exploration to confirm the diagnosis.

Results: These lesions have clinical and radiographic features similar to hemangioma of bone but they do not pose the surgical hemorrhage control problems of hemangiomas.

After exploration, curettage and peripheral osteotomy we expect the patient will have complete bone fill. Follow-up radiographs will be done for evaluation after the procedure.

Conclusion: While these lesions are exceedingly rare and do not present in a consistent manner both clinically and radiographically, it is therefore important to recognize the wide spectrum of their clinical, radiographic, and histological presentations.
\end{abstract}

Keywords: Hemangiolymphangioma, lymphangioma, vascular malformation, mandible

\section{INTRODUCTION:}

These lesions are generally broadly classified into vascular tumours (hemangiomas) and vascular malformations (venous malformations, arteriovenous malformations, lymphatic malformations. Vascular anomalies are mainly divided into two categories: vascular tumours and vascular malformations according to the cellular turnover, histology and clinical findings. Infantile hemangiomas may appear soon after birth and consist of majority of vascular anomalies and are considered the predominant vascular be- nign tumour type composed of rapidly proliferating endothelial cells. [1, 2] Blood vessel architecture is incomplete and surrounded by hyperplastic cells in hemangiomas and other vascular tumours. Vascular malformations are characterized as an error in development of vascular embryologic tissue and consist of progressively enlarging aberrant and ectatic vessels composed of a particular vascular architecture such as veins, lymphatic vessels, venules, capillaries, arteries or mixed vessel type. These lesions could be differentiated from vascular tumors by the fact that they are present at birth, do not have increased endothelial cell turnover, and grow proportionally with the child. Lymphatic malformations are unusual congenital malformations of the lymphatic system, generally occurring in the head and neck region, which are characterized by collections of ectatic lymph vessels that form endothelial lined cystic spaces. $[1,2,3]$ These descriptive tumours and malformations have been categorized based on the architectural assembly of vessels. The intraosseous lesions of the jaw bones, are exceedingly rare developmental anomaly and are not well characterized.

Hemangiolymphangioma is a version of lymphangioma that shows vascular elements. The pathogenesis of these tumours could be of importance in thoroughly understanding the mode of these varying histopathological presentations. [4] At about 50\% of the lesions being noted at birth and $90 \%$ developing by the first 2 years of age and it is equally divided between males and females. [1, 5]

Lymphangioma as a benign hamartomaous lesion, occurs most commonly in the head and neck area, but rarely in the oral cavity. The on the anterior two thirds of tongue is the most common location in the mouth, followed by the lips, buccal mucosa, soft palate, and floor of the mouth. Oral lesions may increase in size, producing macroglossia which can lead to dysfunction in breathing, mastication, deglutition, speech but also displacement of the teeth, with a resulting malocclusion. It can jeopardize normal breathing, particularly during sleep, leading to sleep apnea, and in certain instances, produce a life-threatening upper airway compromise. They can also be present on the palate, buccal mucosa, gingiva and lips. $[1,5,6]$

The tumour with superficial location demonstrates a white pebbly surface that resembles a cluster of translucent vesicles. Lymphangiomas contain clear lymph fluid, but some of the lesion may present as transparent vesicles 
containing red blood cells due to hemorrhage. These with deeper location appear as a nodule or masses without significant change in surface texture or colour and could mimic various soft tissue lesions as hemangioma, amyloidosis, congenital hypothyroidism, neurofibromatosis, primary muscular hypertrophy. Very rare lymphangioma may occur in association with hemangioma. [1]

Progressions in the knowledge of pathogenesis of vascular malformations are continuously changing their treatment protocols, but early recognition allows proper initiation of treatment and prevents the occurrence of complications.

\section{CASE REPORT}

This study presents case of hemangiolymphangioma focusing on the clinical, radiographic, and histologic characteristics and differential diagnostics challenges. Medical records of the patient were reviewed for data on presentation and imaging.

A 46-year-old female patient reported at the Department of Oral \& Maxillofacial Surgery, FDM, MU-Sofia,with radiological findings of radiolucent lesion of the mandible, detected accidently while dental implant planning. Patient had not given a history of trauma or previous oral surgery procedures. On intraoral clinical examination of the patient no other oral pathology was revealed. Radiographic features (CT scan) included a radiolucent lesion without causing root resorption or displacement and no cortical thinning in lingual or buccal aspect of the mandible. (Fig.1 a, b.)

According to the clinical and radiological features, age and the location of the occurrence, giant cell granuloma, aneurismal pseudocyst, idiopathic bone cavity, keratocyst and bone hemagioma could be considered as differential diagnosis.

An exploration biopsy was scheduled and during the procedure a total excochleation of the lesion was performed with peripheral osteotomy under local anesthesia. (Fig. 2) Intraoperative findings showed a bone cavity filled with blood-tinged serous fluid and soft tissue similar to granulations. The excised tissue was submitted for histopathologicalexamination (34397/16.01.2019). It was diagnosed as hemangiolymphangioma, since large lymphatic vessels were lined by flattened endothelial cells. These numerous dilated vessels spaces are filled with either blood cells or lymphatic fluids. The histopathology of scrapings from the bony wall showed no epithelial lining.

Radiographic follow-up will be held after surgery.

Fig. 1 a), b) Radiological findings of the lesion.
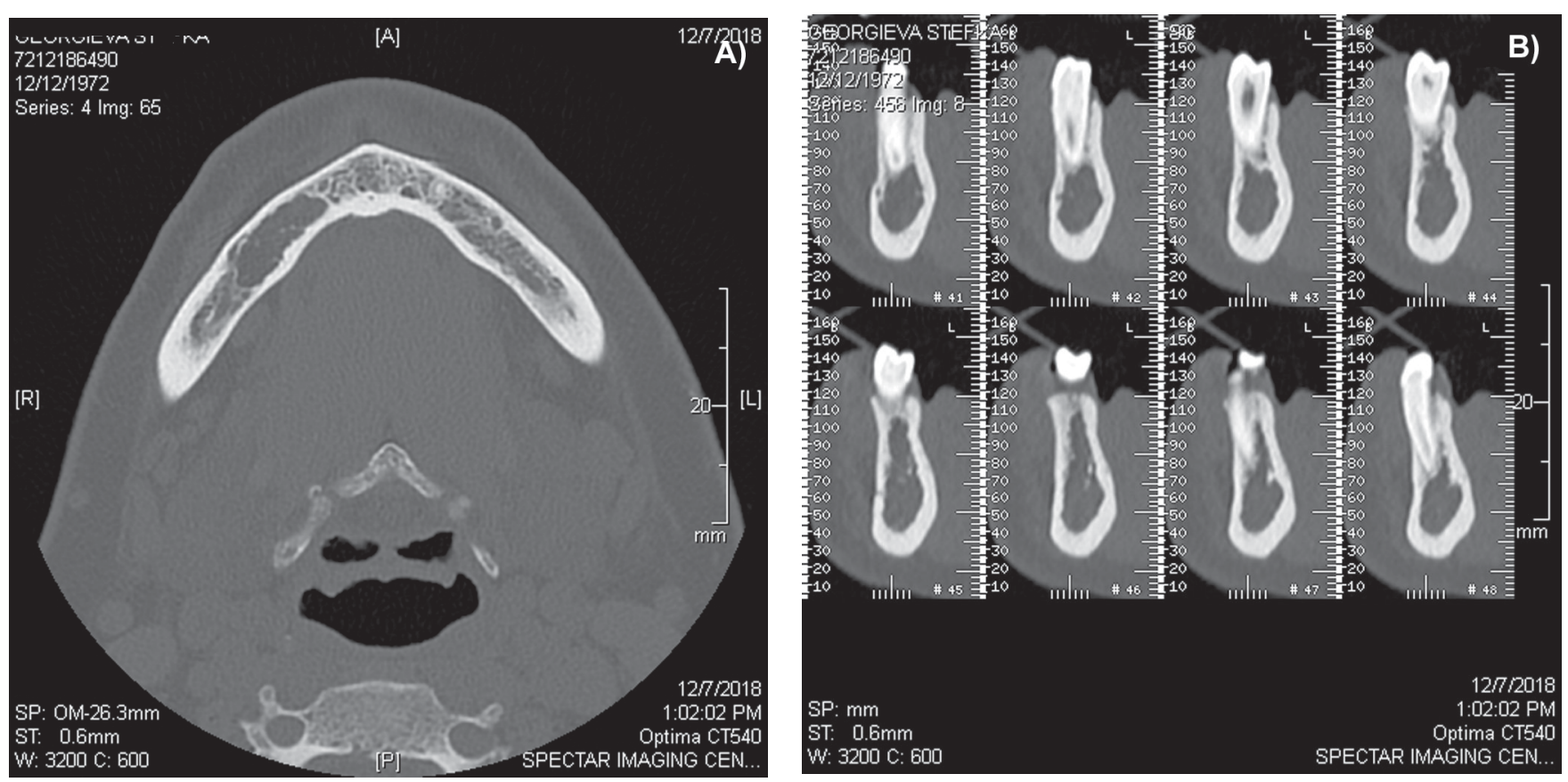
Fig. 2. Intraoperative findings

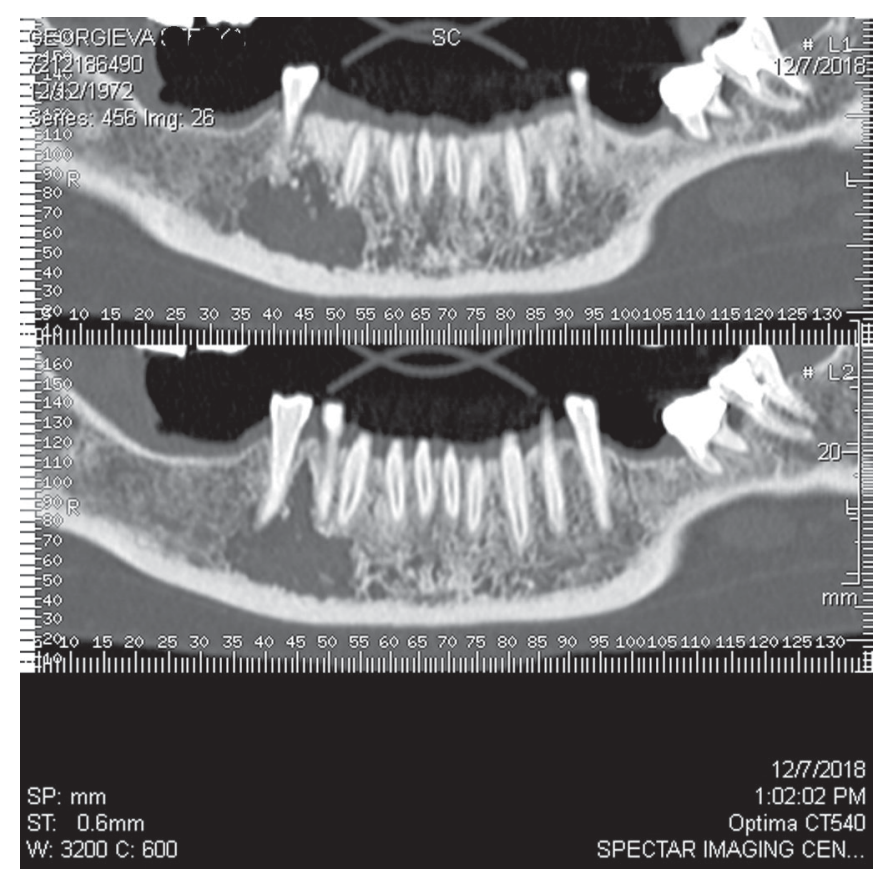

\section{DISCUSSION}

Lymphangioma for the first was described by Virchow in 1854. In 1872, Krester hypothesized that hygromas were derived from lymphatic tissue as well. Nowadays the origin of lesion is considered to be hamartomouscongenital abnormality of lymphatic system rather than true neoplasm which is confirmed by the fact that most lymphangiomas manifest clinically during early childhood and develop in areas where the primitive lymph sacs occur (neck, axilla). Oppositely some theories consider that lymphangioma is a true neoplasm and is result from transformed lymphatic endothelial cells and/or stromal cells. $[1,7,8]$

The pathogenesis of vascular malformations as hemangioma and lymphangioma are interrelated. The sequence of events in embryology of vasculogenesis divides into three stages: the undifferentiated capillary network stage, the retiform developmental stage and the final developmental stage. [9] Two major theories have been proposed to explain the origin of congenital lymphangiomas. [10] The first theory proposes that the lymphatic system develops from five primitive sacs arising from venous system and endothelial outpouchings from the jugular sacs spread centrifugally to form the lymphatic systems. Another theory proposes that the lymphatic system develops from mesenchymal clefts in the venous plexus reticulum and spreads centripetally toward the center of jugular sacs. Lymphangioma develops from congenital obstruction or sequestration of the primitive lymphatic enlargement and the etiology of lymphangioma acquired in adulthood include; trauma, inflammation, and lymphatic obstruction as possible pathogenic mechanism. [1, 11]

Several studies have been published to explain possible lymphangiogenic growth factors involvement in the etiology of lymphatic malformations. These factors comprise vascular endothelial growth factor (VEGF)-C, vascu- lar endothelial growth factor receptor 3 (VEGFR-3), and transcription factor Prox-1, but VEGF-C and VEGFR-3 have shown to be regulators in lymphatic malformed tissue, and both are involved in lymphatic tissue proliferation.[12] Oral lesions are most frequently found on the dorsum of the tongue. The tumour may be detected as well at the floor of the mouth and very rarely in jaw bones. If the tumour is located in a deeper area, it may present as submucosal mass and should be differentiated from hemangioma, amyloidosis, congenital hypothyroidism, neurofibromatosis, leyomioma, rabdomyoma, lipoma, primary muscular hypertrophy etc. [13]

The misunderstanding of the distinction between hemangiomas and vascular malformations leads to diagnostic mistakes. Hemangiomas as a tumour are differentiated from vascular malformations by their clinical appearance, histopathological and biological features.

Lymphatic malformations/lymphangiomas are classified histologically into four categories: lymphangioma simplex (lymphangiomacircumscriptum; cavernous lymphangioma; cystic lymphangioma (cystic hygroma) and benign lymphangioendothelioma (acquired progressive lymphangioma) [14] .

The channels of the lymphatic lesion may be filled with blood: hemangiolymphangioma, which is an uncommon developmental anomaly with a tendency to invade underlying tissues and to recur locally, distinguishing it from the simple lymphangioma or hemangioma. In the present case, numerous large-sized lymphatic channels along with medium- to large-sized channels entrapped with red blood cells, lined by endothelium, were it was subcategorized as hemangiolymphangioma

Treatment of lymphangioma/hemangiolymphangioma is difficult and depends on the size and type and location of lesion, association with anatomic structures, and infiltration to the surrounding tissues. Although spontaneous regression of lesions is rarely encountered, the usual treatment for these lesion is surgical excision. $[15,16,17$, $18]$ Due to a rate of recurrence of nearly $21 \%$, long-term follow-up is essential of these tumorigenic anomalies is. Venous malformations are often difficult to differentiate from lymphatic malformations leading to the development of several lymphatic markers like D2-40 which seems to be useful for distinguishing vascular from lymphatic vessels. [18, 19, 20]

\section{CONCLUSION}

Vascular anomalies hemangioma and lymphangioma are linked in their pathogenesis. The vascular lesions that consist of both blood vessels and lymphatic vessels can be termed as hemangiolymphangioma. Hemangiolymhangioma is extremely rare in the oral cavity, and only a few cases are reported. All suspected cases should be appropriately evaluated. allows

Early recognition and appropriate diagnosis could help for proper initiation of treatment and prevents the occurrence of complications. Surgical excision is the treatment of choice for the most of the lesions. The patient should be followed in long term to rule out any recurrence. 


\section{REFERENCES:}

1. Shetty DC, Urs AB, Rai HC, Ahuja N, Manchanda A. Case series on vascular malformation and their review with regard to terminology and categorization. Contemp Clin Dent. 2010 Oct;1(4):259-62. [PubMed] [Crossref]

2. Drolet BA, Esterly NB, Frieden IJ. Hemangiomas in children. $N$ Engl J Med. 1999 Jul 15;341(3):173-81. [PubMed] [Crossref]

3. Kohout MP, Hansen M, Pribaz JJ, Mulliken JB. Arteriovenous malformations of the head and neck: natural history and management. Plast Reconstr Surg. 1998 Sep;102(3):643-54. [PubMed] [Crossref]

4. Manickam S, Sasikumar P, Kishore BN, Joy S. Hemangiolymphangioma of buccal mucosa: A rare case report. J Oral Maxillofac Pathol. 2017 May-Aug;21(2):282-285. [PubMed] [Crossref]

5. Jeeva Rathan J, Harsha Vardhan BG, Muthu MS, Saraswathy K, Sivakumar N. Venkatachalapathy. Oral lymphangioma: A case report. J Indian Soc Pedod Prev Dent. 2005; 23(4): 185-9. [Crossref]

6. Dinerman WS, Myers EN. Lymphangiomatous macroglossia. Laryngoscope. 1976;86:291-6.

7. Rice JP, Crson SH. A case report of lingual lymphangioma presenting as recurrent massive tongue enlargement. Clin Pediatr (Phila). 1985 Jan; 24(1):47-50. [PubMed] [Crossref]
8. Huang HY, Ho CC, Huang PH, Hsu SM. Co-expression of VEGF-C and its receptors, VEGFR-2 and VEGFR-3, in endothelial cells of lymphangioma. Implication in autocrine or paracrine regulation of lymphangioma. Lab Invest. $2001 \mathrm{Dec} ; 81(12)$ : 1729-34. [PubMed]

9. Yarmand F, Seyyedmajidi M, Shirzad A, Foroughi R, Bakhshian A. Lymphangiohemangioma of buccal mucosa: Report of a rare case. J Oral MaxillofacSurg Med Pathol. 2016; 28:358-61

10. Patel JN, Sciubba J. Oral lesions in young children. PediatrClin North Am. 2003; 50:469-86.

11. Bhayya H, Pavani D, Avinash Tejasvi ML, Geetha P. Oral lymphangioma: A rare case report. Contemp Clin Dent. 2015;6(4):584-587. [PubMed] [Crossref]

12. Itakura E, Yamamoto H, Oda Y, Furue M, Tsuneyoshi M. VEGF-C and VEGFR-3 in a series of lymphangiomas: is superficial lymphangioma a true lymphangioma? Virchows Arch. 2009 Mar;454(3):317-25. [PubMed] [Crossref]

13. Lobitz B, Lang T. Lymphangioma of the tongue. Pediatr Emerg Care. 1995 Jun;11(3):183-5. [PubMed] [Crossref]

14. Meher R, Garg A, Raj A, Singh I. Lymphangioma of tongue. Internet
J Otorhinolaryngology. 2005;3:2.

15. Seong-Soo K. Intraosseous haemangiolymphangioma of the mandible: a case report. J Korean Assoc Oral Maxillo Surgeons. 2003; 29(3): 182-5.

16. Stanescu L, Georgescu EF, Simionescu C, Georgescu I. Lymphangioma of the oral cavity. Rom J Morphol Embryol. 2006; 47(4):373-7. [PubMed]

17. Eveson JW, Pring M. Oral Cavity. In: Cardesa A, Slootweg P, Gale N, Franchi A. (eds) Pathology of the Head and Neck. Springer, Berlin, Heidelberg. 2016; pp.129-177. [Crossref]

18. Kolay SK, Parwani R, Wanjari S, Singhal P. Oral lymphangiomas - clinical and histopathological relations: An immunohistochemically analyzed case series of varied clinical presentations. J Oral Maxillofac Pathol. 2018 Jan;22(Suppl 1):S108-S111. [PubMed] [Crossref]

19. Abe A, Kurita K, Ito Y. Acquired lymphatic malformations of the buccal mucosa: A case report. Clin Case Rep. 2018 Aug 15;6(10):1929-1932. [PubMed] [Crossref]

20. Babu DB, Kumar BR, Boinepally NH, Gannepalli A. A Case of Intraoral Lymphangioma Circumscripta - A Diagnostic Dilemma. J Clin Diagn Res. 2015 Oct;9(10):ZD11-3. [PubMed] [Crossref

Please cite this article as: Deliverska E. Hemangiolymphangioma of the mandible: case report. J of IMAB. 2019 OctDec;25(4):2729-2732. DOI: https://doi.org/10.5272/jimab.2019254.2729

Received: 26/03/2019; Published online: 10/10/2019

\author{
Address for correspondence: \\ Elitsa Georgieva Deliverska \\ Department of Oral and Maxillofacial surgery, Faculty of Dental medicine, \\ Medical University- Sofia. \\ 1, Georgi Sofiiski blvd., Sofia 1431, Bulgaria. \\ E-mail: elitsadeliverska@yahoo.com
}

